\title{
Melhorando a usabilidade de mapas de navegação em hipertextos através de técnicas gráficas de diferenciação
}

\author{
Improving hypertext navigation map usability through graphic differentiation \\ techniques
}

princípios de usabilidade, mapas de navegação, diferenciação

\begin{abstract}
A usabilidade de um sistema é a possibilidade do mesmo ser utilizado facilmente e eficazmente pela gama de usuários aos quais ele se destina, para realizar uma determinada gama de tarefas dentro de cenários ambientais específicos. Visando estudar a influência das técnicas de diferenciação gráfica na usabilidade dos mapas de navegação, este artigo resume os resultados de três fases experimentais, onde foram testadas três diferentes versões do mapa de navegação, com sessenta usuários. Inicialmente foram realizados testes e entrevistas com usuários utilizando o mapa sem diferenciação gráfica, na segunda fase foi analisado o mapa com diferenciação cromática e na terceira fase foram estudados os resultados obtidos pelos usuários na utilização do mapa com diferenciação pictórica. Os resultados demonstraram benefícios da aplicação de técnicas gráficas de diferenciação tanto na performance quanto na satisfação dos usuários.
\end{abstract}

usability principles, navigation maps, differentiation

The usability of a system is defined as its capability of being used easily and effectively by a specific range of users to perform a specific range of tasks within a specific range of environments. Aiming to investigate the effects of graphic differentiation techniques upon site map usability, this article summarises the results of three experimental studies, when three different versions of a site map were tested with sixty users. Initially, a map without differentiation was tested and users interviewed. In the second phase, a map with colour coding was tested, which was followed by the tests involving a map with pictorial differentiation. Results demonstrated several benefits of the application of differentiation techniques in terms of performance and user satisfaction.

\section{Introdução}

Hipertexto pode ser definido como um método de organização de informação no qual o conteúdo é dividido em múltiplos nós de informação que, conectados através de múltiplas ligações, passam a constituir uma rede (Conklin, 1987). A principal particularidade desses nós é o fato de proporcionarem acesso a vastas quantidades de informação e maior controle ao usuário, permitindo que o mesmo escolha os conteúdos a serem explorados.

Entretanto, essa mesma flexibilidade pode levar à desorientação ou sobrecarga cognitiva, devido ao esforço e concentração adicionais necessários à realização concomitante de tarefas de navegação e busca de informações. Uma das soluções propostas na literatura para minimizar tais problemas consiste na implementação de ferramentas de auxílio à navegação, cujo objetivo é melhorar a orientação, a realização de tarefas específicas de busca de informação e o gerenciamento de tarefas concomitantes.

Dentre as ferramentas de auxílio à navegação, as ferramentas de visualização geral têm sido recomendadas por vários autores (Danielson, 2002; Nielsen, 2002; Singh e Kotzé, 2002; Becker, 2004; Kurniawan e Zaphiris, 2005). A ferramenta de visualização geral mais citada pelos mesmos tem sido o mapa de navegação. Os mapas de navegação fornecem auxílio à navegação sem constranger a liberdade de navegação dos usuários, pois dão suporte a praticamente todas as estratégias de navegação. Mais ainda, essas ferramentas podem mostrar aos usuários pontos fundamentais para a orientação, como a visão geral da estrutura, a posição do usuário, áreas já visitadas ou por visitar.

Uma análise dos resultados de pesquisas teóricas e empíricas anteriores revela discrepâncias no que diz respeito ao benefício da utilização de mapas de navegação. Por um lado, 


\section{Infodesıgn}

argumenta-se que mapas de navegação melhoram o mapeamento cognitivo da estrutura do hipertexto (Dias e Souza, 1997) e minimizam a desorientação sem comprometer a liberdade de navegação (Vora e Helander, 1997), além de auxiliar o usuário na busca de informações (Chou e Lin, 1998 | McDonald e Stevenson, 1998). Por outro lado, certas pesquisas demonstraram que o uso de um mapa não melhorou a orientação nem a eficiência na busca de informações (Stanton et al, 2000). Esse tipo de discrepância sugere que a forma de apresentação dos mapas nas pesquisas empíricas tem sido diferenciada, uma vez que as tarefas propostas e procedimentos experimentais são bastante similares.

Cabe investigar, portanto, os efeitos das características dos mapas sobre a navegação dos usuários. Nesse sentido, este estudo se concentra nas características gráficas de representação da estrutura do hipertexto na forma de um mapa global. Mais especificamente, na aplicação de diferenciação cromática e pictórica em mapas globais. Verificamos a influência da aplicação dessas formas de diferenciação sobre a performance de busca de informações dos usuários, desenvolvimento de mapas cognitivos e satisfação com o mapa utilizado durante a tarefa.

\section{Referencial Teórico}

\section{A usabilidade de mapas de navegação}

Segundo Shackel (1991), a usabilidade de um sistema pode ser definida como a possibilidade do sistema ser utilizado facilmente e eficazmente pela gama de usuários aos quais ele se destina na realização de determinadas tarefas dentro de contextos específicos.

Shackel (1991) afirma ainda que a usabilidade de uma ferramenta depende, entre outros fatores, das características do design dessa ferramenta. No caso específico dos mapas de navegação, como essa ferramenta representa a estrutura do hipertexto, a facilidade de utilização dessa ferramenta e o entendimento da estrutura pelo usuário estarão intrinsecamente ligados à forma como a estrutura é representada no mapa. Essa representação pode ser diferenciada em vários aspectos:

- $\quad$ tipo de representação (e.g., árvore hierárquica, rede, lista);

- semântica da representação (e.g., abstrata, metafórica);

- modalidade de representação (e.g., textual, pictórica)

- nível de detalhamento da representação (e.g., quantidade de nós e ligações representadas);

- atualização da representação (e.g., sinalização de áreas já visitadas e indicação da posição corrente do usuário);

- tamanho da representação;

- diferenciação entre os elementos e grupamentos representados.

Porém, apesar da diversidade de aspectos que influenciariam a usabilidade de um mapa de navegação, as recomendações para o projeto desse tipo de ferramenta encontradas na literatura concentram-se principalmente no tipo, semântica, modalidade e tamanho da representação, havendo uma carência de recomendações mais específicas no que se refere à atualização, tamanho, nível de detalhamento e diferenciação entre elementos ou grupamentos representados.

\section{A importância da diferenciação}

Neste artigo, utiliza-se o termo diferenciação referindo-se à distinção formal gráfica entre componentes informacionais presentes em um sistema. Pesquisas anteriores sugerem a utilização de técnicas gráficas de diferenciação para melhorar a interação usuário-sistema e a performance resultante. Lansdale e Ormerod (1994), por exemplo, associam a diferenciação à redução de erros perceptivos. Os autores ressaltam que esses erros ocorrem devido à dificuldade do usuário em distinguir precisamente entre várias alternativas similares, e apontam como uma das formas de reduzir esse tipo de erro em interfaces, a maximização da diferenciação entre os objetos, através da utilização de diversos mecanismos de codificação (e.g., formas, cores, sombras). Mayhew (1992) também aponta como causa para erros perceptivos a insuficiência de indicações perceptivas (perceptual cue) visuais, e recomenda a utilização de diferenciação visual para reduzir erros perceptivos e facilitar tarefas de busca e interpretação de informações.

Nielsen (1995) propõe a utilização de técnicas de diferenciação como uma das formas de se transmitir informação contextual ao usuário, reduzindo o problema de homogeneidade em 
hipertextos e, consequentemente, minimizando a desorientação dos usuários. O autor recomenda também o destaque de pontos de referência (landmarks) nos mapas de navegação como forma de facilitar a navegação em hipertextos.

Além de diminuir a ocorrência de erros perceptivos e facilitar a busca de informações, a utilização de mecanismos de diferenciação pode trazer outros benefícios igualmente importantes, como o desenvolvimento de um mapa cognitivo do espaço hipertextual.

Kim e Hirtle (1995) mencionam a diferenciação entre os quatro fatores relacionados às características do hipertexto que têm maior influência na aquisição de mapas cognitivos, e argumentam que diferenciar tipos de nós de informação ou áreas do hipertexto auxiliaria os usuários a estabelecer e reconhecer pontos de referência (landmarks) dentro do hipertexto, que consiste em uma das etapas envolvidas no desenvolvimento de um mapa cognitivo.

Entretanto, apesar de todos os potenciais benefícios, a questão da diferenciação em hipertextos vem sendo tratada apenas como uma recomendação proposta por alguns pesquisadores baseando-se em teorias cognitivas. Necessita-se de pesquisas empíricas que verifiquem as reais implicações da aplicação da diferenciação nos mapas de navegação sobre a performance e a satisfação de seus usuários.

Neste estudo, escolhemos como mecanismos diferenciadores entre os diversos nós de informação do mapa o uso da cor e de imagens relacionadas ao conteúdo de cada nó de informação. Discorremos, portanto, sobre as vantagens de cada um desses elementos gráficos de acordo com os resultados de pesquisas teóricas e empíricas anteriores.

\section{As vantagens do uso da cor}

Segundo Arnheim (1994), de todos os componentes da imagem, a cor é a mais eficiente dimensão de discriminação. Corroborando essa afirmação, Guimarães (2003) destaca que a cor pode ser usada em um projeto para estabelecer diferenças, contribuir para a organização das informações, selecionar a parte do todo e ressaltá-la, criando hierarquias tanto em nível de importância quanto em sequência de leitura. Por extensão, a discriminação cromática contribui para relacionar elementos que não são apresentados simultaneamente (como no caso dos nós de informação de um hipertexto), criando vínculos entre essas informações.

Laar e Deshe (2002) ressaltam que a codificação cromática pode ser utilizada para destacar relações quantitativas entre informações posicionadas em diferentes níveis hierárquicos na estrutura do sistema ou para explicitar as relações entre informações em um mesmo nível. Brawn e Snowden (1999) apud Laar e Deshe (2002) acrescentam que a codificação cromática pode ser utilizada para segmentar um display em elementos relevantes da tarefa para auxiliar o operador a focar nesses elementos.

Ainda sobre os potenciais benefícios da codificação cromática, Sanders e McCormick (1993) mencionam o auxílio desse mecanismo às tarefas de busca. Uma das razões para essa vantagem da cor sobre outros mecanismos de codificação seria o fato de que cores "captam o olhar" do usuário mais rapidamente do que outros mecanismos de codificação visual.

Yeh e Wickens (2001) explicam que os benefícios da codificação cromática para a busca de informações decorrem do processamento pré-atencional da informação (preattentive information processing), ou seja, a discriminação cromática seria realizada de forma praticamente automática em um estágio ainda bastante preliminar do processamento da informação. Segundo os mesmos autores, a codificação cromática auxiliaria também o princípio da compatibilidade por proximidade (proximity compatibility principle), princípio esse que permite a integração de informações provenientes de diferentes fontes. Através da proximidade espacial ou gráfica (no caso da cor), minimiza-se o tempo e a carga na memória de curta duração necessários à comparação e integração das informações.

Pesquisas empíricas anteriores comprovaram os benefícios do uso da cor como mecanismo de codificação e diferenciação. Laar e Deshe (2002), por exemplo, exploraram as implicações do uso da codificação cromática em displays de salas de controle. Os resultados do experimento demonstraram que a diferenciação cromática das áreas reduziu o tempo de busca a elementos-chave da tarefa, sendo também a forma preferida para representar o display. Os participantes consideraram que esse tipo de diferenciação tornou o display mais atrativo, mais fácil de usar e menos fatigante visualmente.

Ling e Schaik (2002) investigaram o uso da cor para diferenciar frames de navegação e áreas de conteúdo em websites. Dentro do frame de navegação, os autores manipularam ainda a relação cor do frame - cor dos links do menu. Os resultados da pesquisa revelaram que o uso de diferentes combinações de cor afetou tanto a precisão na busca de informações quanto o tempo de reação dos participantes. O uso da cor influenciou ainda a preferência dos usuários e a 


\section{Infodesıgn}

qualidade percebida do display.

Yeh e Wickens (2001) compararam o uso de codificação cromática, codificação por intensidade e filtragem de informação em mapas eletrônicos. Os resultados da pesquisa demonstraram que o uso da codificação cromática facilitou a busca de informações nos mapas e diminuiu o tempo de busca, sendo mais eficaz inclusive que o mecanismo de filtragem. a cor auxiliou os participantes a focar sua atenção em objetos de diferentes domínios e posteriormente compará-los e integrar as informações.

Smith et al. (1995) examinaram os efeitos do uso da cor em mapas computadorizados de sistemas de informação geográfica (GIS) sobre a performance de busca visual e grupamento perceptual. Os autores aplicaram cores diferenciadas a categorias distintas de símbolos nos mapas, comparando essa forma de diferenciação com diferenciação por formato ou por completude da forma. A codificação cromática se mostrou superior nos resultados relativos à leitura do mapa e à percepção dos arranjos formados por símbolos de uma mesma classe.

Wolfson e Case (2000) investigaram os efeitos de cores e sons sobre o nível de atenção, percepção e performance de usuários de jogos computadorizados, sendo diferentes cores aplicadas ao fundo do jogo. O uso da cor influenciou o progresso dos usuários ao longo do jogo, seu nível de atividade, o quão alerta se mantiveram e a quantidade de erros cometidos. Cores diferenciadas também geraram opiniões diferentes dos usuários como com relação a quão empolgante eles consideraram o jogo.

\section{As vantagens do uso de imagens}

Segundo Loschky (2001), o uso de imagens minimiza várias das limitações humanas de atenção visual e de memória, facilitando nossa percepção e apreensão de informações visuais. No que concerne à limitação de atenção visual, o autor afirma que as imagens nos auxiliam de duas importantes maneiras: direcionando nossa atenção e permitindo que cada pessoa leve o tempo que necessita para explorar a informação visual. Mais ainda, quando um sistema transmite informação através de imagens, ao invés de exigir que o usuário a memorize, o usuário pode liberar parte dos recursos da memória para envolvê-los em outros processos, como relacionar e integrar informações.

Gershon (1995) argumenta que as imagens possuem várias vantagens de processamento. Segundo o autor, as imagens transmitem informação mais rapidamente do que as palavras, pois as pessoas normalmente olham e reconhecem imagens mais rapidamente do que lêem e interpretam palavras. Para situações em que o objeto representado é familiar, as pessoas são capazes de entender o conteúdo de uma imagem mesmo que a representação seja extremamente simplificada. É o caso, por exemplo, dos pictogramas. Sander e McCormick (1993) destacam que essa forma de representação é preferível à forma textual pois imagens não necessitam de recodificação.

Trumbo (1999] aponta uma variedade de situações em que a utilização de imagens pode facilitar o aprendizado: ilustração de conceitos, solução de problemas, clarificação de idéias, desenvolvimento de conceitos, comparação entre alternativas, correção de concepções errôneas e sumarização de tópicos. A autora cita Barry (1997) para ressaltar o aspecto motivacional das imagens no aprendizado, uma vez que reagimos emocionalmente às imagens antes mesmo que as entendamos cognitivamente. Mais ainda, enquanto a linguagem escrita necessita ser processada cognitivamente, as imagens são processadas na mesma rota perceptiva (perceptual pathway) que nossas experiências diretas.

Atualmente, os sistemas computadorizados interativos têm utilizado imagens para representar diversas funções em contextos que variam desde aplicativos educacionais até sistemas de comércio eletrônico. Pesquisas empíricas têm investigado os benefícios que o uso de imagens pode trazer para a performance e a satisfação dos usuários quando utilizam esses sistemas.

Hong et al (2004) investigaram a utilização de imagens como forma de apresentação da informação em páginas de listagem de produtos em sites de comércio eletrônico. Os resultados de sua pesquisa demonstraram que o uso de imagens dos produtos em conjunto com suas respectivas marcas, quando comparadas ao uso somente das marcas, proporcionou maior eficiência e eficácia na busca de informações, maior facilidade de comparação entre produtos, melhor recordação das marcas disponíveis no site e uma atitude mais positiva dos usuários quanto ao design das telas e à agradabilidade do site como um todo.

De Angeli et al. (2005) exploraram a aplicação de imagens em mecanismos de autenticação eletrônicos. No sistema proposto, o usuário, ao invés de necessitar recordar uma senha, teria que reconhecer uma imagem previamente escolhida. Os autores basearam sua proposta no efeito da superioridade das imagens (picture superiority effect). De acordo com esse efeito, os seres humanos têm uma vasta memória visual, e imagens tendem a ser lembradas 
melhor e por mais tempo do que palavras. A superioridade das imagens, segundo os autores, também pode ser explicada pela teoria da dupla-codificação (dual-coding theory) que atribui às imagens uma maior probabilidade de serem codificadas tanto visualmente quanto verbalmente na memória. Essa vantagem das imagens seria explicada ainda pelo fato de sua representação mental ser mais rica e detalhada do que a das palavras, tornando as imagens mais facilmente diferenciáveis no momento da recordação.

\section{Metodologia da Pesquisa}

\section{Design Experimental}

O design experimental da pesquisa utilizou como único fator (variável independente) a diferenciação, com três níveis de variação: mapa e telas sem diferenciação (versão controle), mapa e telas com diferenciação cromática, mapa e telas com diferenciação pictórica.

As variáveis dependentes consistiram na performance de navegação, eficácia na realização da tarefa, recordação da estrutura do hipertexto, facilidade de realização da tarefa e benefícios percebidos da utilização do mapa. Cada variável dependente é composta de diversas medidas, conforme explicitado na tabela 1.

Tabela 1: Variáveis dependentes e medidas correspondentes

\begin{tabular}{|c|c|c|}
\hline Variável dependente & Medidas & Forma de medição \\
\hline Performance de navegação & $\begin{array}{l}\text { T(1): tempo na busca primária } \\
T(2) \text { : tempo na revisitação } \\
\text { T(tot): tempo total } \\
\text { St(tot): número de telas visitadas } \\
\text { ST(tot): quantidade total de telas visitadas } \\
\text { MAP(tot): total de visitas ao mapa }\end{array}$ & $\begin{array}{l}\text { registro da navegação } \\
\text { registro da navegação } \\
\text { registro da navegação } \\
\text { registro da navegação } \\
\text { registro da navegação } \\
\text { registro da navegação }\end{array}$ \\
\hline Eficácia na realização da tarefa & $\begin{array}{l}\text { Tg(1): telas-chave acessadas durante a busca- } \\
\text { primária } \\
\operatorname{Tg}(2) \text { : telas-chave acessadas durante a } \\
\text { revisitação } \\
\text { Tg(tot): número de telas-chave acessadas } \\
\text { Recal(1): recordação das telas-chave } \\
\text { acessadas durante a busca primária }\end{array}$ & $\begin{array}{l}\text { registro da navegação } \\
\text { registro da navegação } \\
\text { registro da navegação } \\
\text { preenchimento de formulário } \\
\text { eletrônico }\end{array}$ \\
\hline $\begin{array}{l}\text { Recordação da estrutura do } \\
\text { hipertexto }\end{array}$ & $\begin{array}{l}\text { Rec(tg): recordação do nome das telas-chave } \\
\text { Loc(tg): recordação da localização das telas- } \\
\text { chave na estrutura do hipertexto } \\
\text { Rec(ot): recordação do nome de telas não } \\
\text { associadas à tarefa } \\
\text { Loc(ot): recordação da localização de telas não } \\
\text { associadas à tarefa }\end{array}$ & $\begin{array}{l}\text { desenho de mapa (pós- } \\
\text { navegação) } \\
\text { desenho de mapa (pós- } \\
\text { navegação) } \\
\text { desenho de mapa (pós- } \\
\text { navegação) } \\
\text { desenho de mapa (pós- } \\
\text { navegação) }\end{array}$ \\
\hline & $\begin{array}{l}\text { Sk (tg): total de recordações das telas-chave } \\
\text { Sk(ot): total de recordações de telas não } \\
\text { associadas à tarefa }\end{array}$ & $\begin{array}{l}\text { desenho de mapa (pós- } \\
\text { navegação) } \\
\text { desenho de mapa (pós- } \\
\text { navegação) }\end{array}$ \\
\hline Dificuldade de realização da tarefa & $\begin{array}{l}\text { Dificuldade na busca primária } \\
\text { Dificuldade na revisitação }\end{array}$ & questionário \\
\hline $\begin{array}{l}\text { Benefício percebido da utilização do } \\
\text { mapa }\end{array}$ & $\begin{array}{l}\text { Auxílio do mapa na busca primária } \\
\text { Auxílio do mapa na revisitação } \\
\text { Auxílio das cores de fundo } \\
\text { Auxílio da cor e das imagens nos links }\end{array}$ & $\begin{array}{l}\text { questionário } \\
\text { questionário } \\
\text { questionário } \\
\text { questionário }\end{array}$ \\
\hline
\end{tabular}




\section{Inf0desıgn}

Como variáveis de controle utilizaram-se a estrutura e o conteúdo do hipertexto, a diagramação das telas, a representação da estrutura do hipertexto no mapa (em forma de rede), a representação, o posicionamento e a atualização dos links nas telas e no mapa.

No que concerne à participação dos participantes, optou-se pelo design de medidas únicas (between-subject design) para evitar o efeito da aprendizagem da estrutura do hipertexto e da tarefa a ser realizada. Desse modo, cada participante navegou em apenas uma versão do hipertexto utilizando o mapa correspondente.

\section{Versões geradas a partir do design experimental}

O hipertexto utilizado no experimento possui 45 nós de informação interligados. Cada nó de informação representa uma barraca em uma feira de frutas fictícia. Optou-se por esse tema devido às inúmeras possibilidades de associação entre as frutas (e.g., cor, época, região de produção). Cada tela representa uma barraca da feira, possuindo um texto sucinto sobre as características da fruta e produtos derivados comercializados. O design das telas é predominantemente textual.

O mapa global representa a estrutura do hipertexto em forma de rede. Cada nó da rede corresponde a uma barraca da feira. Todas as ligações entre os nós foram representadas, não havendo qualquer tipo de filtragem. O mapa é estático, mas os links já visitados são marcados com coloração diferente e a cada acesso o mapa sinaliza o local onde o usuário se encontra com a legenda "você está aqui".

Na versão controle, as telas e os nós do mapa utilizaram a mesma cor de fundo (bege). Na versão com diferenciação cromática, utilizou-se a cor predominante da fruta no fundo da tela e no respectivo nó no mapa. Na versão com diferenciação pictórica manteve-se a cor bege de fundo e cada tela recebeu uma imagem da fruta correspondente. Cada nó do mapa também recebeu essa mesma imagem em formato reduzido junto ao link textual.

Figura 1: Exemplo de tela e parte superior do mapa com diferenciação cromática
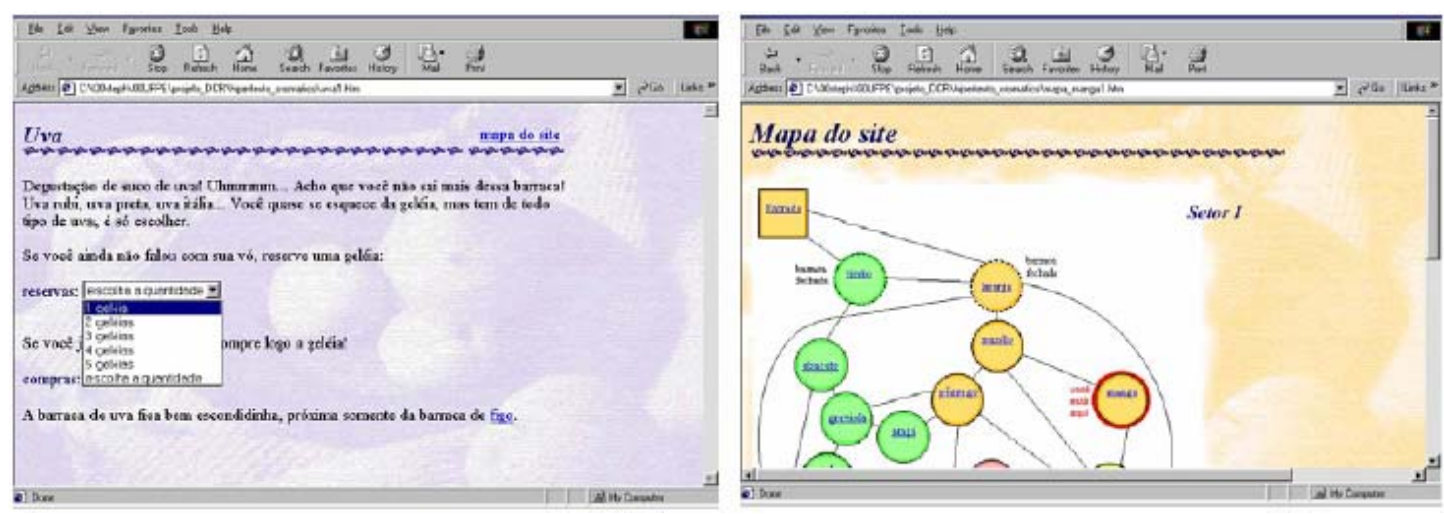

Figura 2: Exemplo de tela e parte superior do mapa com diferenciação pictórica
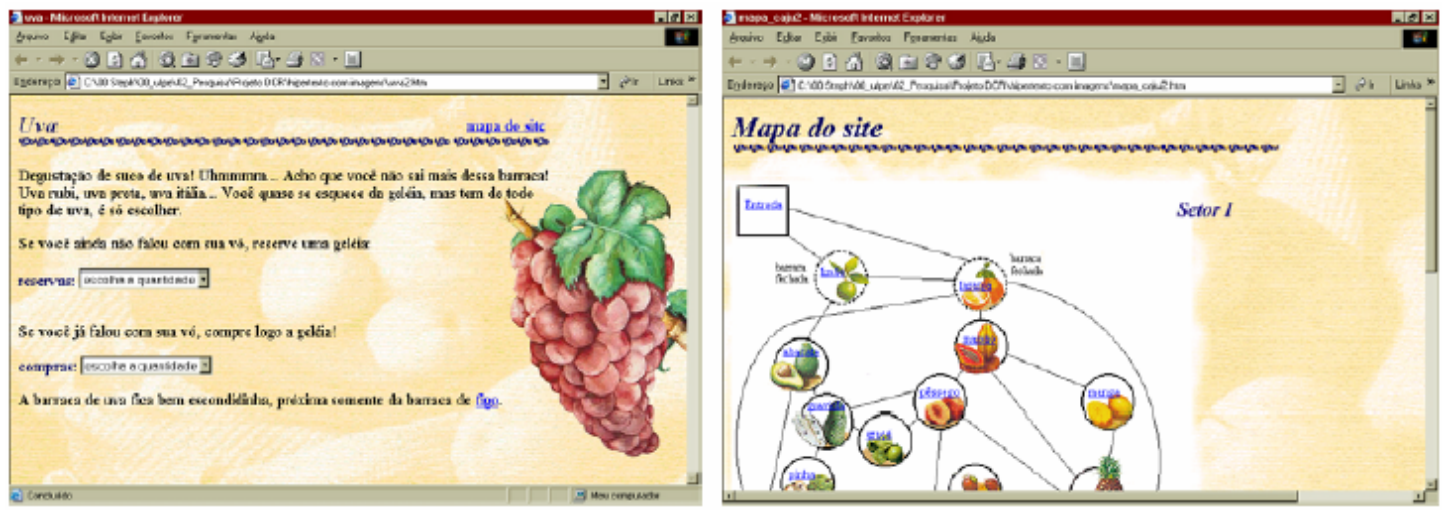

\section{Participantes}

Sessenta estudantes de graduação e especialização provenientes de diversos departamentos da UFPE participaram voluntariamente da pesquisa. Cada participante realizou a tarefa computadorizada proposta individualmente e utilizando apenas uma versão do hipertexto/ mapa (20 participantes - versão controle, 20 participantes - versão com diferenciação cromática, 20 participantes - versão com diferenciação pictórica). 


\section{Procedimento}

Cada participante foi recebido individualmente na sala da pesquisadora e recebeu instruções gerais sobre o objetivo do experimento e as etapas envolvidas (tarefa computadorizada, desenho e questionário). Após as instruções iniciais, o participante realizou a tarefa computadorizada, sem restrição de tempo. As instruções sobre as atividades da tarefa computadorizada foram apresentadas em telas do próprio hipertexto, à medida que o participante completava cada etapa.

A tarefa solicitada envolvia a busca primária de informações e a revisitação de telaschave. Primeiramente, o usuário deveria encontrar 5 telas contendo informações chave, em seguida dirigir-se a uma tela cujo título era fornecido. Na segunda parte da tarefa, o usuário deveria informar o nome das 5 telas-chave (de memória) e retornar às mesmas a partir desse ponto do hipertexto. Optou-se por uma tarefa que envolvesse praticamente todos os tipos de tarefas informacionais realizadas por usuários de sistemas hipertextuais.

Após a tarefa computadorizada, propôs-se a tarefa surpresa de desenho de um mapa para o site, sem que o participante pudesse navegar o site novamente. Este procedimento foi adotado para evitar que, ao realizar a tarefa sabendo que deveria desenhar o mapa do site, o usuário desenvolvesse algum mecanismo de memorização dessa estrutura, ao invés de simplesmente realizar a tarefa de busca de informação naturalmente. A intenção foi captar o aprendizado involuntário (incidental learning - Baddeley, 1997) dessa estrutura apenas como consequência do processo de navegação e busca de informações.

Após o desenho do mapa do site, os participantes responderam um questionário sobre a realização da tarefa e as características do mapa disponibilizado.

\section{Resultados da pesquisa}

Nesta seção apresentamos os resultados do questionário e do registro de navegação dos usuários pelo sistema hipertextual.

\section{Performance de Navegação}

A análise das medidas objetivas de performance (coletadas durante a realização da tarefa de busca de informações pelos participantes) revela que a diferenciação cromática afetou consideravelmente a quantidade de acessos ao mapa, oferecendo certos benefícios aos participantes em relação aos que utilizaram o mapa sem diferenciação e com diferenciação pictórica (vide tabela 2). Os usuários que utilizaram o mapa com diferenciação pictórica mostraram-se mais rápidos no tempo de execução da busca primária, bem como mais eficientes na diminuição do total de telas visitadas.

Tabela 2: Variáveis dependentes de navegação e resultados (ANOVA)

\begin{tabular}{l|l|l|l|l|l}
\hline Variáveis & SEM DIF & DIF CROMA & DIF IMG & F [anova] & sig \\
\hline $\begin{array}{l}\text { T1: tempo de realização das tarefas } \\
\text { da } 1^{\mathrm{a}} \text { fase }\end{array}$ & $8: 51$ & $6: 57$ & $6: 42$ & 11,967 & $\mathrm{p}<.01$ \\
\hline $\begin{array}{l}\text { T2: tempo de realização das tarefas } \\
\text { da } 2^{\mathrm{a}} \text { fase }\end{array}$ & $3: 21$ & $2: 21$ & $4: 06$ & 11,017 & $\mathrm{p}<.01$ \\
\hline T_TOT: tempo total & $12: 12$ & $9: 18$ & $10: 47$ & 10,087 & $\mathrm{p}<.01$ \\
$\begin{array}{l}\text { ST TOT: quantidade total de telas } \\
\text { visitadas }\end{array}$ & 51,45 & 37,35 & 36,70 & 30,091 & $\mathrm{p}<.01$ \\
\hline MAP_TOT: total de visitas ao mapa & 20,90 & 19,20 & 23,70 & 4,844 & $\mathrm{p}<.01$ \\
\hline
\end{tabular}

\section{Eficácia na Realização da Tarefa}

Benefícios foram verificados entre os usuários do mapa com diferenciação cromática, destacando-se entre eles a redução no tempo de busca e na quantidade de telas visitadas para completar a tarefa informacional proposta. A diferenciação cromática também contribuiu significativamente para a recordação das telas-chave no intervalo entre a tarefa de busca primária e a revisitação das telas-chave; como conseqüência, observa-se também um aumento significativo na precisão da tarefa pelos usuários desse mapa, ao contrário dos que utilizaram o mapa com diferenciação por imagens (vide tabela 3). 


\section{InfĐdesıgn}

Tabela 3: Variáveis dependentes de realização da tarefa e resultados (ANOVA)

\begin{tabular}{l|l|l|l|l|l}
\hline Variáveis & SEM DIF & DIF CROMA & DIF IMG & F [anova] & sig \\
\hline $\begin{array}{l}\text { TG1: quantidade de telas-chave da 1a } \\
\text { fase }\end{array}$ & 4,75 & 5,00 & 5,00 & 6,333 & $\mathrm{p}<.01$ \\
\hline $\begin{array}{l}\text { RECAL1: recordação das telas-chave } \\
\text { acessadas durante a busca primária }\end{array}$ & 3,20 & 4,45 & 3,90 & 6,585 & $\mathrm{p}<.01$ \\
\hline $\begin{array}{l}\text { TG2: quantidade de telas-chave da 2 } \\
\text { fase }\end{array}$ & 4,55 & 4,80 & 4,60 & 0,952 & $\mathrm{p}>.05$ \\
\hline TG_TOT: quantidade de telas-chave & 9,30 & 9,80 & 9,60 & 2,983 & $\mathrm{p}<.05$ \\
\hline
\end{tabular}

\section{Recordação da Estrutura do Hipertexto}

Este foi o único aspecto em que não se observaram benefícios da aplicação de técnicas gráficas de diferenciação. Percebe-se a ausência de diferenças significativas em praticamente todas a medidas coletadas, com exceção da recordação de telas chave não relacionadas à tarefa. Provavelmente, devido ao curto tempo de exposição ao hipertexto, os usuários não conseguiram realmente desenvolver algum conhecimento espacial relevante de sua estrutura informacional.

Tabela 4: Variáveis dependentes de recordação da estrutura do hipertexto e resultados (ANOVA)

\begin{tabular}{|c|c|c|c|c|c|}
\hline Respostas & SEM DIF & DIF CROMA & DIF IMG & F [anova] & sig \\
\hline $\begin{array}{l}\mathrm{RC}(\mathrm{tg}) \text { : recordação do nome das } \\
\text { telas-chave }\end{array}$ & 4,15 & 4,20 & 3,60 & 1,209 & $p>.05$ \\
\hline $\begin{array}{l}\text { RC(ot): recordação do nome de telas } \\
\text { não associadas à tarefa }\end{array}$ & 12,70 & 9,85 & 9,70 & 3,624 & $p<.03$ \\
\hline $\begin{array}{l}\mathrm{Lc}(\mathrm{tg}) \text { : recordação da localização das } \\
\text { telas-chave na estrutura do hipertexto }\end{array}$ & 2,05 & 2,15 & 2,60 & 0,618 & $p>.05$ \\
\hline $\begin{array}{l}\text { LG(ot): recordação da localização de } \\
\text { telas não associadas à tarefa }\end{array}$ & 2,50 & 4,55 & 3,70 & 2,798 & $p>.05$ \\
\hline $\begin{array}{l}\text { Sk(tg): total de recordações das } \\
\text { telas-chave }\end{array}$ & 0,62 & 0,64 & 0,62 & 0,022 & $p>.05$ \\
\hline $\begin{array}{l}\text { Sk(ot): total de recordações de telas } \\
\text { não associadas à tarefa }\end{array}$ & 0,30 & 0,43 & 0,22 & 10,418 & $p<.01$ \\
\hline
\end{tabular}

\section{Dificuldade de realização da tarefa}

Quando questionados sobre a dificuldade em encontrar telas-chave pela falta de diferenciação no mapa, os entrevistados do mapa sem diferenciação gráfica responderam que não dificultou (vide tabela 5), o que não se observou nos resultados sobre dificuldade na busca primária por telas-chave (vide tabela 6), onde os mesmos responderam que houve dificuldade.

Uma discrepância ainda maior se observa nos resultados obtidos na dificuldade em reencontrar as telas-chave pela falta de diferenciação no mapa, onde a maior parte dos usuários disse dificultar muito (vide tabela 5), mesmo esse dado não se observando nas respostas dos usuários do mapa sem diferenciação, que disseram ter tido pouca dificuldade na realização da tarefa para reencontrar as telas-chave. Observa-se, portanto, que a falta de diferenciação prejudica o reencontro das telas-chave, pelos usuários.

Tabela 5: Respostas sobre a dificuldade na busca de informações pela falta de diferenciação

\begin{tabular}{l|c|c|c|c|c|c}
\cline { 2 - 7 } & \multicolumn{3}{l|}{ Dificuldade em encontrar telas-chave } & \multicolumn{3}{l}{ Dificuldade em reencontrar telas-chave } \\
\hline Respostas & SEM DIF & DIF CROMA & DIF IMG & SEM DIF & DIF CROMA & DIF IMG \\
\hline dificultou muito & 02 & & & 11 & & \\
\hline dificultou um pouco & 07 & & & 03 & & \\
\hline não dificultou & 10 & & & 06 & & \\
\hline
\end{tabular}

De forma geral, os resultados demonstram que, apesar de ter havido um pouco de dificuldade pelos usuários na busca primária para encontrar as telas-chave, não houve muita dificuldade para reencontrá-las, ocorrendo, portanto um equilíbrio entre os mapas sem diferenciação e com técnicas de diferenciação gráfica. Observa-se também que a dificuldade em encontrar e reencontrar as telas-chave diminui com a aplicação da técnica de diferenciação cromática e pictórica (vide tabela 6). 
Tabela 6: Respostas sobre a dificuldade na busca de informações

\begin{tabular}{l|l|l|l|l|l|l}
\cline { 2 - 7 } & \multicolumn{4}{l|}{ Dificuldade em encontrar as telas-chave } & \multicolumn{3}{l}{ Dificuldade em reencontrar telas-chave } \\
\hline Respostas & SEM DIF & DIF CROMA & DIF IMG & SEM DIF & DIF CROMA & DIF IMG \\
\hline muita dificuldade & 07 & 02 & 05 & 02 & 00 & 05 \\
\hline alguma dificuldade & 13 & 13 & 10 & 08 & 05 & 05 \\
\hline pouca dificuldade & 00 & 05 & 05 & 08 & 13 & 10 \\
\hline nenhuma dificuldade & 00 & 00 & 00 & 02 & 02 & 00 \\
\hline
\end{tabular}

\section{Benefícios Percebidos da Utilização do Mapa}

Ao serem perguntados a respeito do auxílio que o mapa proporcionava na busca primária de informações, os usuários responderam que ajudou muito, principalmente com a utilização da diferenciação pictórica. Em relação ao auxílio do mapa para reencontrar as telas, os participantes responderam que o mapa ajudou bastante, especialmente com a utilização da diferenciação cromática (vide tabela 7).

Tabela 7: Respostas sobre o auxílio do mapa na busca de informações

\begin{tabular}{l|l|l|l|l|l|l}
\cline { 2 - 7 } & \multicolumn{4}{l|}{ Ajuda do mapa na primeira procura } & \multicolumn{3}{l}{ Ajuda do mapa para reencontrar telas } \\
\hline Respostas & SEM DIF & DIF CROMA & DIF IMG & SEM DIF & DIF CROMA & DIF IMG \\
\hline ajudou muito & 12 & 10 & 20 & 13 & 19 & 10 \\
\hline ajudou um pouco & 06 & 08 & 00 & 06 & 00 & 05 \\
\hline não ajudou & 02 & 02 & 00 & 01 & 01 & 05 \\
\hline
\end{tabular}

\section{Formas de Diferenciação}

Quando questionados sobre o auxílio do uso da cor como elemento facilitador de diferenciação os entrevistados, que utilizaram os mapas sem diferenciação e com diferenciação por imagens, foram favoráveis (vide tabela 8).

Tabela 8: Respostas sobre o uso de cor como elemento facilitador de diferenciação

\begin{tabular}{l|l|l|l}
\hline Respostas & SEM DIF & DIF CROMA & DIF IMG \\
\hline facilitaria muito & 10 & - & 04 \\
\hline facilitaria um pouco & 08 & - & 11 \\
\hline não facilitaria, poluiria & 02 & - & 05 \\
\hline
\end{tabular}

Alguns usuários do mapa com diferenciação cromática afirmaram que o uso de cores de fundo nas telas do mapa ajuda a evitar a confusão de telas, enquanto o mesmo número de entrevistados respondeu que o uso da cor não auxiliou em nada. De qualquer forma, observa-se que o uso da cor auxilia em vários outros aspectos (vide tabela 9).

Tabela 9: Respostas sobre o auxílio de cores de fundo e imagens nas telas do mapa

\begin{tabular}{l|l|l|l}
\hline Auxilio da diferenciação & SEM DIF & DIF CROMA & DIF IMG \\
\hline orientação & - & 03 & 14 \\
\hline não confundir telas & - & 07 & 05 \\
\hline pontos de referência & - & 04 & - \\
\hline busca primária & - & - & - \\
\hline recordação telas-chave & - & 03 & 04 \\
\hline revisitação das telas-chave & - & 06 & \\
\hline entendimento da estrutura & - & 03 & 15 \\
\hline NÃO auxiliou & - & 07 & - \\
\hline
\end{tabular}




\section{Infødesıgn}

Os usuários do mapa sem diferenciação e com diferenciação cromática foram favoráveis ao uso de imagens nas telas do mapa como elemento facilitador de diferenciação (vide tabela 10). Quando perguntados sobre o auxílio do uso de imagens nas telas do mapa, os usuários do mapa com diferenciação pictórica responderam que facilita os processos de orientação e entendimento geral da estrutura (vide tabela 09).

Tabela 10: Respostas sobre o uso de imagens como elemento facilitador de diferenciação

\begin{tabular}{l|l|l|l}
\hline Respostas & SEM DIF & DIF CROMA & DIF IMG \\
\hline facilitaria muito & 10 & 06 & - \\
\hline facilitaria um pouco & 08 & 08 & - \\
\hline não facilitaria, poluiria & 02 & 06 & - \\
\hline
\end{tabular}

Ao serem questionados sobre o auxílio do uso de cores de fundo nos links do mapa, os usuários do mapa com diferenciação cromática, responderam que essa técnica ajuda principalmente a achar os links de forma mais rápida e no aspecto da orientação.

Tabela 11: Respostas sobre o auxílio de cores de fundo e imagens nos links

\begin{tabular}{l|l|l|l}
\hline Respostas & SEM DIF & DIF CROMA & DIF IMG \\
\hline orientação & - & 09 & 10 \\
\hline não confundir links & - & 08 & 04 \\
\hline pontos de referência & - & 12 & 05 \\
\hline busca primária & - & & \\
\hline recordação telas-chave & - & 04 & 05 \\
\hline revisitação das telas-chave & - & 09 & \\
\hline entendimento da estrutura & - & 03 & \\
\hline achar links + rápido (ñ só pela leitura) & - & 10 & 15 \\
\hline
\end{tabular}

\section{Conclusão}

Este projeto teve como objetivo verificar a influência da utilização de mapas com técnicas de diferenciação nos aspectos relacionados à performance de navegação, eficácia na realização de tarefas e orientação por usuários de hipertextos, realizando tarefas de sondagem e busca de informações específicas.

Através desta pesquisa, pôde-se comprovar a eficácia da utilização de técnicas de diferenciação em mapas de navegação, onde se observou melhora considerável na performance de navegação e realização de tarefas. Portanto, das técnicas utilizadas, a diferenciação cromática apresentou os resultados mais significativos, principalmente na diminuição do tempo de busca de informações e do número de telas do mapa visitadas, e no auxílio à recordação de telas e aspectos de distinção das mesmas, bem como na influência sobre a precisão das tarefas realizadas.

Os desdobramentos deste projeto experimental envolvem, numa quarta fase de pesquisa, a verificação da eficácia do mapa com diferenciação cromática e pictórica (simultaneamente) aplicadas nas telas e links do mapa, tendo como objetivo a validação dos princípios de usabilidade aplicados na construção do mapa assim como o melhoramento da representação da estrutura do hipertexto nos mapas de navegação.

\section{Referências}

ANGELI, A., COVENTRY, L, JOHNSON, G. e RENAUD, K. (2005). Is a picture really worth a thousand words? Exploring the feasibility of graphical authentication systems. Int. J. Human-Computer Studies, 63. p. 128-152.

ARNHEIM, R. (1994). Arte e Percepção Visual. São Paulo: Editora Pioneira.

BADDELEY, A. (1997). Human Memory: theory and pratice. Hove: Taylor \& Francis. 
CHOU, C. e LIN, H. (1998). The Effect of Navigation Map Types and Cognitive Styles on Learner's Performance in a Computer-Networked Hypertext Learning System. Journal of Educational Multimidia and Hypermidia, 7(2-3), 151-176.

CONKLIN, J. (1987). Hypertext: an Introduction and Survey. IEEE Computer, 20(9), 17-41.

DANIELSON, D.R. (2002). Web navigation and the behavioral effects of constantly visible site maps. Interacting with Computers, 14(5), 601-618.

DIAS, P. e SOUZA, A. P. (1997). Understanding Navigation and Disorientation in Hypermidia Learning Environments. Journal of Educational Multimidia and Hypermidia, 6, $173-$ 185.

GERSHON, N. (1995). The power and the frailty of images: is a picture worth a thousand words? Computer Graphics, nov/95. p. 35-36.

GUIMARÃES, L. (2003). As Cores na Mídia. São Paulo: Editora AnnaBlume.

KIM, H. e HIRTLE, S. C. (1995). Spatial Metaphors and Disorientation in Hypertext Browsing. Behavior \& Information Technology, 14. p. $239-250$.

LAAR, D. V. e DESHE, O. (2002). Evaluation of a visual layering methodology for colour coding control room displays. Applied Ergonomics, 33. p. 371-377.

LANSDALE, M. W. e ORMEROD, T. C. (1994). Understanding Interfaces: a handbook of human-computer dialogue. London: Academic Press.

LING, J. e SCHAIK, P. V. (2002). The effect of text and background colour on visual search of Web pages. Displays, B.V. 23. p. 223-230.

LOSCHKY, L. (2001). Some things that pictures are good for: an information processing perspective. University of Illinois at Urbana-Champaign. Human Perception and Performance Group. Beckman Institute for Advanced Science and Technology.

MAYHEW, D. J. (1992). Principles and Guidelines in Software User Interface Design. London: Prentice Hall.

MCDONALD, S. e STEVENSON, R. J. (1998). Effects of Text Structure and Prior Knowlegde of the Learner on Navigation in Hypertext. Human Factors, 40(1), p. 18-27.

NIELSEN, J. (1995). Navigating Large Information Spaces. In Multimidia: the internet and beyond. London: AP Professional.

SANDERS, M. S. e MCCORMICK, E. J. (1993). Human Factors in Engineering and Design. New York: McGraw - Hill.

SHACKEL, B. (1991). Usability - Context, Framework, Definition, Design and Evaluation. In B. Shackel e S. Richardson (eds.), Human Factors for Informatics Usability. Cambridge: Cambridge University Press. p.21-37.

SMITH, W, DUNN, J., KIRSNER, K. e RANDELL, M. (1995). Colour in map displays: issues for task-specific display design. Interacting with computers, vol7, n². p.151-165.

STANTON, N. CORREIA, A. P. e DIAS, P. (2000). Efficacy of a Map on Search, Orientation and Access Behaviour in a Hypermidia System. Computers \& Education, 35. p.263-279.

TRUMBO, J. Visual Literacy and Science Comunication (1999). Science Communication, v 20, n०4. p.409-425.

VORA, P. R. e HELANDER, M. G. (1997). Hypertext and its Implications for the Internet. In Handbook of Human-Computer interaction. Amsterdam: Elvieser Publisher.

WOLFSON, S. e CASE, G. (2000) The effecs of sound and colour on responses to a computer game. Interacting with computers, 13. p.183-192.

YEH, M. e WICKENS, C. (2001). Attentional filtering in design of eletronic map displays: a comparison of color coding, intensity coding, and decluttering techniques. Human Factors vol. 43, n4. p. 543-562. 